increased in quantity, and $\mathrm{Mr}$ Rossell was consulted in reference to treatment.

After the application of topical remedies, and the administration of iron tonics, the discharge ceased, but it was observed that this cessation was followed by the development of grave constitutional disturbance, which passed off on the reappearance of the discharge. The purulent matter ejected after these periods of arrest exceeded a large bucketful in volume.

In the month of May the mare suffered from a severe attack of enteritis, and, after recovery from this the uterine discharge increased greatly in quantity, and rapid emaciation of the animal's body took place.

Considerable oedema of the hind limbs was also observed at this period whenever diminution of the uterine flux occurred.

The discharge throughout was purulent in character, mixed with cheesy material, and of an extremely foetid odour.

The mare was destroyed on the night of the 3oth of July, and the uterus was forwarded to the college.

Examination of the uterus showed that it was of an enormous volume-almost as large as a gravid uterus at full term; that its walls were thickened to the extent of an inch, and of fibrous consistence; but the most remarkable change had taken place in the mucous membrane; it was greatly thickened and rugose, and bestudded over its whole extent with nodular elevations, some of them polypoid in form, and varying in size from a vetch seed to a large pea. The condition of the mucous membrane afforded ample explanation of the inability of the therapeutic measures applied by Mr Rossell with the object of effecting a cure.

Its cavity contained a quantity of cheesy matter.

\title{
A CASE OF TUBERCULOSIS IN THE HORSE
}

By JAmes Cooke, F.R.C.V.S., Scarborough.

THE subject of this communication was a bay gelding, aged six years, belonging to Mr William Hardcastle of Bingley, Yorks, from whom I got the following history.

About eighteen months ago the animal had a slight attack of influenza, and since that time he appeared unthrifty, and more or less dejected when standing in the stable, or when standing after exercisc. He was noticed to have a haggard appearance, but he regained his usual spirits after he had been warmed to work. In March last he was found to be ailing, and it was then observed that he stood in a peculiar manner, and that he had a difficulty in getting his head to the ground when in the act of eating. He was then under treatment for indigestion.

Some six weeks afterwards he was driven over to Scarborough, a distance of about 70 miles, and for a few weeks after his arrival he appeared to be fairly healthy, but it was soon noticed that he was losing flesh and not doing well, and he was therefore again put under treatment. Several professional opinions were obtained in the meantime, most of them agreeing that the animal's brain or spine was affected. 
On the I $5^{\text {th }}$ of July I was asked to sce the animal, and, after making arrangements with the veterinary surgeon who had the case in hand, I made an examination and found the following symptoms.

Symptoms.-General appearance dejected, condition poor, lethargic, slight stiffness in walking and in turning round, appetite good, bowels and kidneys acting regularly (a few weeks previously the animal had diuresis). Nothing abnormal to be found in throat or rectum. Pulse $60^{\circ}$; mucous membranes pallid ; temperature IOI . Slight cough, and a little discharge from the nostrils.

On auscultating and percussing the chest, I found a mucous rale in the bronchial tubes, the lower half of the right lung consolidated, the upper part of it being similar to the left lung, with circumscribed patches of consolidation over the whole surface. The animal regularly lay in a natural position, on both sides of chest; but a very peculiar symptom was the singular manner in which the animal comported itself when the head was lowered during the act of eating or drinking. The nose was then poked out, the neck appeared rigid, and the forelimbs were placed as wide apart as possible, one being pushed out beyond the animal's nose; the hind limbs were straddled in a similar manner. This peculiar crab-like position $\mathrm{I}$ attributed to pneumogastric nervous irritation.

Diagnosis.-Chronic broncho-poneumonia, prognosis-death.

Treatment.-The animal being a great favourite with the owner, I was requested to prescribe for it, and I recommended cod-liver oil, combined with mineral and vegetable tonics and iodide of potassium. I occasionally called to see the horse, but found no difference in the symptoms, except that the mucous membranes had lost much of their pallidity, and were now slightly reddened. On August 5th I visited the animal in company of the owner, and recommended it to be immediately destroyed, as the emaciation had become greater. The joints of the limbs and the sheath were swollen, the breath was foetid, pulse increased to $72^{\circ}$, respirations 36 ; the animal grunted a little on turning around. The horse was walked to the knacker's, a distance of a quarter of a mile, and destroyed on the 6th August.

Post-mortem.-On visiting the slaughterer's yard I was informed that there was some difficulty in separating the skin from the muscles of the back, it having become firmly united, but there did not appear to be any spinal injury. On opening the abdomen the bowels were noticed to be extremely pallid, but otherwise healthy. The spleen was very much diseased and greatly enlarged, weighing 16 lbs. and being adherent to the ribs and diaphragm. The kidneys and lungs were pale in colour, and the former weighed $4 \mathrm{lbs}$, each. The lungs were studded over their whole surface with tuberculous deposits. The lower half of the right lung was consolidated. Nothing abnormal was detected in the heart or brain.

Sections of the lungs, liver, spleen, heart, and kidneys were sent to Professor M'Fadyean, who kindly reported that he had examined the specimens microscopically, and had ascertained, beyond any doubt, that the lesions were tubercular_- "the bacilli being enormously abundant."

Remark. - That this animal may have been infected through contact with cows is not at all unlikely, as it was stabled for some time with eight of them about two years before its death. 